\title{
Exploring Online Student Engagement During COVID-19 Pandemic in Mongolia
}

\author{
Zoljargal Dembereldorj ${ }^{1}$ \\ ${ }^{1}$ Center for Foreign languages, Division of Humanities, School of Arts and Sciences, National University of \\ Mongolia, Ulaanbaatar, Mongolia \\ Correspondence: Dembereldorj, Zoljargal, Center for Foreign languages, Division of Humanities, School of Arts and \\ Sciences, National University of Mongolia, Ikh surguuliin gudamj-1 P.O.Box - 46A/523, 210646, Ulaanbaatar, \\ Mongolia.
}

Received: January 29, 2021

Accepted: April 30, 2021

Online Published: May 6, 2021

doi:10.5430/ijhe.v10n7p10

URL: https://doi.org/10.5430/ijhe.v10n7p10

\begin{abstract}
Student online engagement has become a challenge for higher education in Mongolia during the COVID-19 pandemic. This study explores student engagement in online learning of Mongolian higher education during the lockdown period. The study assessed differences in student engagement across gender, the tools students used to study, their level of study, and their field of study. It also determined the associations between variables. The data were collected online using the questionnaire developed by Dixson (2015), the scale to measure student online engagement (OST) with four variables: skills, emotion, participation, and performance. The tests of Kruskal-Wallis, Shapiro-Wilk, Cramer's V, Point biserial as well as Spearman rho were used for the analyses. The most significant variables to measure student engagement were participation and performance. One of the important results was that the internet access was highly correlated with the performance variable $(\mathrm{p}=.00)$. The study did not find any significant differences or correlation for "emotion" expressing the devotion and commitment to the online study.
\end{abstract}

Keywords: Covid-19, online student engagement, higher education, non-parametric, Mongolia

\section{Introduction}

In the recent decade, online learning has become easily available with the rise of massive online open courses and has shown its way to the future of education. Online courses have been provided mainly by higher education institutions in the United States. Siemens (2015) stated that online course was the way to satisfy the needs of the diverse population of students and the massification of higher education. Similarly, Meyer (2014) noted that higher education institutions have started to deliver online courses to provide more access to the increasing number of students as well as to keep the retention rates and successful graduation. Hew (2015) defined that "the main purpose of online learning is to offer learners access to education at their own pace and time, as well as lowering the average overall per-learner cost." Online learning, thus have the potential to provide access to the learners and help higher education institutions to retain their rates in the retention of the students.

Due to the pandemic of COVID-19, online learning has become even more ubiquitous as it is considered to be the sole solution to provide education during the period of social distancing and any forms of lockdown around the world. To ensure community safety, online education has become to serve an essential role to retain "normal" education provision through the internet. Amemado (2020) argues that online provision of education at higher education institutions has now become imperative to meet the needs of all common students and sustain the teaching as normal as possible during the pandemic. Dhawan (2020) documented that educational institutions of all levels in India have no choice but to shift traditional classes into online classes with reluctance from teachers, instructors, and educational institutions. In China, where the first cases of COVID-19 were announced, "millions of faculty members started to teach in front of a computer screen, and their students have to stay at home and take the courses through the internet" (Bao, 2020). The study conducted in the United States reported that faculty members had started to adapt to online teaching along with a swift shift from traditional to online classes (Johnson, Veletsianos, \& Seaman, 2020). Hence, online learning and the provision of education through the internet may have already become a new normal as UNESCO launched the idea of "next normal."

With a changing priority of online learning in the educational sector, its purpose is not limited to serve as a remedy 
for mass higher education, ever-increasing student population, and retention. Its purpose now is deemed to serve a role as in traditional learning which is face-to-face learning in the classroom. In other words, the role of online learning during the lockdown shifted to take a role of traditional education. Even though it has now become obvious to state, it is important to note that online education, in general, is now compulsory as never before. Based on this assumption, the study explores student engagement in online learning in a higher education institution in Mongolia. Moreover, there are few studies on student engagement in online learning during the lockdown caused by Covid-19. Casewise, online learning, online education, and online teaching had not been introduced in Mongolia as other countries where higher education institutions provided online teachings to some extent such as accepting courses learned through online platforms, or those students who prefer to study in distance due to some inevitable situations. Hence, the purpose of this study is to explore student engagement in online learning in a higher education institution by comparing student engagement measurement with gender, a level of study, a field of study, the tools to study, and internet access in Mongolia.

\section{Higher Education in Mongolia and Covid-19 Responses}

Mongolia is a country located between China and Russia with a population of over three million and a large landscape of 1.5 million $\mathrm{km}$ square. The capital is Ulaanbaatar where half of the population reside. The country is categorized to be a lower-middle-income country according to the World Bank (World Bank, 2020). A statistical office of Mongolia documented, there are 839 schools with 34073 full-time teachers and 680.8. thousand pupils as of 2020. In higher education, there are 147,293 students which consist of 57,830 males and 89,463 females as of 2020 ; there are 95 higher education institutions including 21 public or state higher educations and 71 private higher education institutions as of 2019 (Mongolian Statistics Office, 2020). The prestigious universities in Mongolia are considered to be public universities providing all levels of education - a bachelor's degree, a master's degree, and a doctoral degree. They were first established during the Soviet era in the 1940s where top-tier Soviet scholars taught classes and many prominent Mongolian scholars were born (Dembereldorj, 2020). Since the 1990s the demand for higher education has increased in which resulted to open private higher education institutions in the country. The pedagogical approach was a traditional classroom instruction until the coronavirus pandemic. Online means of instruction were still new, besides the talks on MOOCs and voluntary self-study from TedX, Khan Academy, Coursera, and so forth in a general public sphere.

Since February 2020, higher education institutions in Mongolia have begun to run their courses online as a preventative measure and a caution. "Lessons learnt from previous outbreaks prompted this early action in addition to the closure of educational institutions and aggressive promotion of public awareness" (Erkhembayar et al., 2020). The first domestic transmission was reported on the $10^{\text {th }}$ of November, 2020, until which the coronavirus was documented to be imported cases from abroad. (WHO, 2020). When the first local case was tested positive for coronavirus, the State Emergency Commission announced an immediate lockdown in the country. One of the sectors that were in an urgent need to shift from face-to-face into online communication was the educational institutions. All educational institutions resumed online teachings beginning from that time.

Higher education institutions started to offer their courses online using different platforms such as university-specific portal systems, other commercial platforms such as google classroom, Microsoft Teams, and Facebook. For instance, the National University of Mongolia issued an order to teach classes online using its portal system and Microsoft Teams. Instructors were allowed to teach both asynchronous and synchronous manners. The most commonly observed mode was asynchronous in which instructors uploaded PowerPoint files with or without audio; as well as recorded videos. Some online classes were held in an asynchronous mode where instructors organized meetings with students. Student evaluation was the most contested issue as many instructors discussed the topic through online groups of instructors. Along with online course provision, students in many higher education institutions raised issues of reducing tuition fees and questioned the quality of classes provided online. They are the few issues to mention for further investigation related to online learning in higher education in Mongolia. This study illuminates the possibilities of online courses in Mongolia by examining student engagement in online learning during the lockdown period.

\section{Literature Review}

During the Covid-19 pandemic, online student engagement has become equally important as higher education institutions transitioned from a traditional face-to-face approach of instructions into a virtual classroom where instructors and students meet through special platforms on the internet and conduct their classes. The definition of student engagement is a contested and ever-discussed issue that is embedded in many aspects of fields. Axelson and Flick (2010) argued that student engagement needs to concern if it is used "as an accountability measure" for student 
engagement in learning or "as a variable in educational research" to decipher student behavior in learning. Similarly, Kahu (2013) argued that student engagement is complex and multidimensional in which we need to consider different aspects by taking an account of antecedents, engagement, and consequences. Thus, scholars usually approach student engagement from multidimensional perspectives.

Trowler (2010) proposed the typology of engagement to understand student engagement: behavioral engagement such as attendance in the classroom, emotional engagement such as espousing interests in the class context, and cognitive engagement such as likely to challenge his or herself. On the other hand, Kahu (2013) proposed four perspectives: "the behavioral perspective, the psychological perspective, the socio-cultural perspective, and the holistic perspective." A behavioral perspective views student engagement from student behavior reported by themselves and do not necessarily consider the thinking skills such as critical and analytic thinking; a psychological perspective points out the internal psychological state and process of the student; a socio-cultural perspective emphasizes the social context of the student experience; and a holistic perspective views qualitative approach to be important to study student engagement in-depth (Kahu, 2013). In the more practical approach proposed by Kuh (2003) clarifying that student engagement has two aspects one of which is time and effort that students put into educational activities, and the other is institutional effort to manage available resources and providing opportunities to support student involvement.

There are a good number of studies on online education, online learning, online teaching (Hew, 2015; Ellis \& Bliuc, 2019; Jacobs, 2013; Henrie, Halverson \& Graham, 2015; Matias, \& Wolf, 2013; Kahn, Everington, Kelm, Reid, \& Watkins, 2017; Paulsen \& McCormick, 2020; Kim \& Bonk, 2006; Wallace, 2003; Keengwe \& Kidd, 2010). "Online learning is a way of learning that students use online learning platform to learn, and an online learning platform is an online learning environment composed of text materials, audio and video, multimedia courseware and other learning resources" (Hu \& Li, 2017, pp. 40). Similarly, "online learning is a learning takes place partially or entirely over the internet" (Means, et. al., 2009, pp. 9).

With the rise of online learning, student engagement in online learning has become a central issue for researchers and scholars. $\mathrm{Hu}$ and $\mathrm{Li}$ (2017) argued that instructors can monitor and ensure student engagement by grasping their attention with different teaching strategies in the classroom, whereas in online learning, student engagement can be influenced by factors that are not controllable by the instructors, and it is at their will to be engaged. As cited by Chakraborty and Nafukho (2014), no online communication can replace those actions in the classroom that we need to deal face-to-face. Given the current situation of lockdown due to the pandemic, student engagement in online learning is mandatory for instructors and higher education institutions to "normally" run classes through the internet using different platforms. Hence, it is important to explore student engagement in an "imperative" online learning caused by the pandemic situation.

Studies explained student online engagement from different approaches. For instance, Dixson (2010) explored channels of interactions and actions that lead to high student engagement in online learning. The study found that student-student and instructor-student communication are strongly correlated with high engagement (Dixson, 2010). In the study by Jaggars and $\mathrm{Xu}$ (2016), the students were found to emphasize interpersonal interactions between students and instructors as well as the frequency in communication. Similarly, Paulsen and McCormick (2020) proposed more collaborative learning and meaningful interaction between instructors and students during the online study. Bolliger and Martin (2018) found that students preferred learner-learner engagement strategies in online learning. Robinson and Hullinger (2008) found a difference in gender and major of participants in online learning engagement. Colorado and Eberle (2010) concluded that graduate students demonstrated a high level of self-regulated learning in terms of student characteristics. In line with mobile technology such as smartphones, Matias and Wolf (2013) explored that collaboration, communication as well as creation have strengthened student engagement in online learning.

Recently, scholars have proposed constructs and measurements to understand student engagement, particularly in an online environment. Hew (2015, pp. 426) organizes the model of online student engagement around self-determination theory that postulates the individual to have three essential needs: "autonomy, relatedness, and competence." Autonomy corresponds to the behavioral aspect (doing); relatedness corresponds to the affective or emotional aspect (feeling); and competence corresponds to the cognitive aspects (thinking) (Hew, 2015). Based on his model, Hew (2015) suggests the guideline to effectively engage online students: "course information, course sources, interaction, active learning, frequent monitoring of learning, and making meaningful connections."

With a qualitative study, Kahn et al., (2017) extended the view of student engagement in online learning emphasizing the student-agency and his/her reflexivity in learning, specifically collective reflexivity. Handelsman, 
Briggs, Sullivan, and Towler (2005) proposed online student engagement measurement with its reliability and validity of the constructs which includes four factors of skills, emotions, participation, and performance. The construct was established to be reliable and valid to measure student online engagement ranging from .76 to .82 (Handelsman et al.,2005). In a similar vein, Dixson (2015) applied the online student engagement scale proposed by Handelsman et al.,(2005) to measure self-reported student engagement with an online tracking system of student behavior. The researcher found that online student engagement positively and significantly correlates with student behaviors in an online course. It indicates that the given measurement tool for online student engagement has the potential to assess student engagement in online learning. Drawing from the previous studies, the researcher asks the following questions: Is there a difference in student engagement in online learning across gender, tools used to study, a level of study, and a field they are studying? How do students differ in engaging in online learning in terms of skills, participation or interaction, emotions, and performance? Is there an association between skills, participation or interaction, emotions and performance with gender, tools used to study, a level of study, and a field they are studying? This study explores student engagement in online learning of Mongolian higher education during the lockdown period caused by Covid-19.

\section{Method}

\subsection{Sampling and Data Collection}

First, the researcher created an online questionnaire link using google forms. Then, the researcher asked faculty members of one state university to invite students to participate in the online questionnaire. To reflect equal voices of different students from different fields as well as to ensure a general central tendency of the student engagement, the researcher selectively asked faculty members from different fields. Faculty members agreed and asked students to participate by emails, portals systems, and web pages. It was voluntary for the students to participate in the questionnaire. Initially, the requested students-participants were estimated to be approximately 400. The online questionnaire received 223 responses in total from the students. The data collection took place between November and December of 2020 during the strict lockdown period.

\subsection{Instrument}

The current study employs the instrument developed by Dixson (2015) to measure student engagement in online learning - the online student engagement scale (OSE). Based on the previously developed scales for student engagement, the OSE considers student engagement behavior specifically in online learning. Reliability scored .91 with factors loading of over .60. External validity was tested using tracks of student behavior in a learning management system which results in $r=.48$ with $\mathrm{p}<.001$. There are four factors: skills, emotion, participation, and performance with a total of 19 items. The skills include "study regularly, stay up on reading, look over class notes, be organized, listen/read carefully, take good notes over readings, PPT, video lectures;" the emotion includes "put forth an effort, find ways to make materials relevant, apply to my life, find ways to make materials interesting, really desire to learn;" the participation includes "have fun in online chats, participate actively in forums, help fellow student, engage in online conversations, post regularly in forums, get to know other students;" and the performance includes "do well on tests, and get good grades." The researcher also added an item asking about access to the internet considering the student life situation in Mongolia. The students were asked to evaluate the given items on a Likert scale ranging from 1 (not characteristic of me) to 5 (very much characteristic of me).

\subsection{Sample Characteristics}

The questionnaire asked the student gender, a field of study, a level of study, tools they use for the study, and an instrument with 19 items to measure student engagement. The sample size is 223 , consisting of 74 male students and 149 female students, all of which 24 are freshmen, 49 sophomore students, 81 junior students, 57 senior students, 10 master students, and 2 doctoral students. In terms of field of study, 31 reported to be in humanities, 15 is in natural science, 79 in social science, 2 in legal studies, 81 in applied science, 11 in other fields and 4 did not report the field of their study.

A Shapiro-Wilk's test (p>.05) (Shapiro and Wilk, 1965) and a visual examination of histograms showed that the data was not normally distributed for gender with skewness of -.719 ( $\mathrm{SE}=.163)$ and kurtosis of -1.496 ( $\mathrm{SE}=.324)$, a level of study with skewness of -.004 ( $\mathrm{SE}=.163$ ) and kurtosis of $-.304(\mathrm{SE}=.324)$, a field of study with skewness of -.229 $(\mathrm{SE}=.164)$ and kurtosis of $-1.094(\mathrm{SE}=.327)$, tools for study with skewness of $.137(\mathrm{SE}=.163)$ and kurtosis of .706 $(\mathrm{SE}=.324)$. As for the items, all items were also not normally distributed: skills with skewness of -.339 (SE=.163) and kurtosis of -.279 (SE=.324), emotion with skewness of $-.352(\mathrm{SE}=.163)$ and kurtosis of -.578 ( $\mathrm{SE}=.324)$, participation with skewness of $-.352(\mathrm{SE}=.163)$ and kurtosis of $-.512(\mathrm{SE}=.324)$, and performance with skewness of $-.169(\mathrm{SE}=.163)$ and kurtosis of $-.304(\mathrm{SE}=.324)$. It can be viewed that the data was not normally distributed in 
which the conventional procedure would be the analysis of a non-parametric approach.

\section{Results}

This section presents results for hypothesis testing to answer the research questions. The first part reports on the result for the test of comparison, and the second part introduces the result from the test for associations.

\subsection{Results for Test of Comparison}

Shapiro-Wilk's test rejected the null hypothesis suggesting to opt for the examination of a non-parametric approach in this study. To answer our first research question, we posit the following hypothesis:

H1: There is a significant difference between gender and skills, emotions, participation, and performance of online student engagement.

To evaluate the differences between female and male students in terms of skills, emotion, participation, and performance of the online student engagement was tested using a Kruskal Wallis's test. The test revealed insignificant differences (Asymp. Sig. = .691) in emotion, and (Asymp. Sig. = .644) in performance. However, the test revealed significant differences $($ Asymp. Sig. $=.044)$ in skills, and (Asymp. Sig. $=.033)$ in participation across gender (male, $n=74$; female, $n=149$ ).

$\mathrm{H} 2$ : There is a significant difference between a level of study and skills, emotion, participation, and performance of online student engagement.

Similarly, test with Kruskal Wallis's test revealed that there is an insignificant difference across a level of study (freshmen, $n=24$; sophomore, $n=49$; junior, $n=81$; senior, $n=57$; master's, $n=10$ and doctoral level, $n=2$ ) in skills $($ Asymp. Sig. $=.550)$, emotion $($ Asymp. Sig. = .395), participation $($ Asymp. Sig. = .090), and performance $($ Asymp. Sig. = .198).

H3: There is a significant difference between tools for study and skills, emotion, participation, and performance of online student engagement.

The hypothesis was tested with Kruskal Wallis's test revealing that there is an insignificant difference in skills $($ Asymp. Sig. $=.097)$, emotion $($ Asymp. Sig. $=.398)$, and participation $($ Asymp. Sig. $=.168)$. However, the test showed significant difference in performance (Asymp. Sig. $=.000$ ) across tools the student uses for study (cellular/smartphone, $\mathrm{n}=44$; personal laptop/tablet/desktop, $\mathrm{n}=156$, laptop/ tablet/desktop borrowed, $\mathrm{n}=22$, other, $\mathrm{n}=1)$.

H4: There is a significant difference between fields of study and skills, emotion, participation, and performance of online student engagement.

A final test with Kruskal Wallis's test showed that there is an insignificant difference in skills (Asymp. Sig. $=.165)$, and emotion (Asymp. Sig. = .464), whereas significant difference in participation (Asymp. Sig. = .014), and performance (Asymp. Sig. $=.027$ ), across the field of study (Humanities, $n=31$, natural science, $n=15$, social science, $\mathrm{n}=79$, law, $\mathrm{n}=2$, applied science, $\mathrm{n}=81$, other, $\mathrm{n}=11$ ).

\subsection{Results for Test of Association}

Since Kruskal Wallis's test showed few options for testing association with given variables, we opt to test the association with the variables that are found to have a significant difference. Here we test if there is a significant association between the estimated significant dependent and independent variables. We use point biserial correlation to show the association between gender and skills and participation. We test the hypothesis as follows:

H1: There is a significant association between gender and skills and participation in student online engagement.

The result of point biserial analysis showed that there is no significant association between gender and skills with $r$ $=.122, \mathrm{p}=.069$. However, there is a significant association between gender and participation in online student engagement with estimated $r=.134$ and $p=.000$. Thus, gender difference weakly $(r=.134)$ but significantly associates with participation in online student engagement.

Table 1. Point biserial correlation

\begin{tabular}{lcccc}
\hline & n & Skills & Participation & Gender \\
\hline Skills & 223 & 1.000 & & \\
Participation & 223 & $.482 * *$ & 1.000 & \\
Gender & 223 & .122 & $.134 * *$ & 1.000 \\
\hline \multicolumn{1}{c}{$* \mathrm{p}<01$} & & &
\end{tabular}

$* * \mathrm{p}<.01$ 
Further, we use a Cramer's V test for analysis of association. A Cramer's V test is used to test the association between 3 or more categorical and continuous variables (Corder \& Foreman, 2011; Field, 2013). We assess the association between tools for study and performance in student online learning to reveal the strength of the association. The following hypotheses were tested:

$\mathrm{H} 2$ : There is a significant association between tools for study and performance in student online engagement.

The test revealed that there is no significant association between the tools for study and performance in online student engagement. The value for Cramer's test is .228 with $p=.070$. Hence, the null hypothesis is accepted.

H3: There is a significant association between a field of study and participation and performance in student online engagement.

We assess the association between a field of study and participation and performance similarly with a Cramer's test. The result showed that there is no significant association between the fields of study and participation with the value of $.296, p=.899$. However, there is a significant association between the field of study and performance in online student engagement with $\mathrm{V}=.253, \mathrm{p}=.002$. Thus, the field of study associates significantly with the reported performance in online student engagement.

Moreover, we look at the specific item that indicates the association within the significant variables. Gender is associated specifically and significantly with the item "engaging in the conversation online (chat, discussion, email)" with $\mathrm{V}=.216, \mathrm{p}=.034$. Gender may have a special effect on participation in terms of communicating online with other students and work in collaboration.

Similarly, the item-specific association between the field of study and performance showed significant association with both items "getting a good grade" with $\mathrm{V}=.216, \mathrm{p}=.004$, and "doing well on the tests/quizzes" with $\mathrm{V}=.191$, $\mathrm{p}=0.43$. Each item shows that the field of study or the field of the students may have an effect on the performance, especially the grades they receive.

Table 2. Spearman Rho's Correlation

\begin{tabular}{lllllll}
\hline & $\mathbf{N}$ & Skills & Emotion & Participation & Performance & Internet access \\
\hline Skills & 223 & 1.000 & & & & \\
Emotion & 223 & $.591^{* *}$ & 1.000 & & & \\
Participation & 223 & $.456^{* *}$ & $.485^{* *}$ & 1.000 & & \\
Performance & 223 & $.464^{* *}$ & $.578^{* *}$ & $.600^{* *}$ & 1.000 & \\
Internet access & 223 & $.207^{* *}$ & $.210^{* *}$ & $.199 * *$ & $.272^{* *}$ & 1.000 \\
\hline$* * \mathrm{p}<.01$ & & & & & &
\end{tabular}

In a final analysis of association, we use Spearman rho's test for non-parametric data to assess the relationship with rank-order. The researcher conducted a correlation across variables: skills, emotion, participation and performance, and internet access. The results showed a strong relationship between performance and participation with $\mathrm{rs}=.600$, $\mathrm{p}=.000$; a moderate correlation between skills and emotion with $\mathrm{rs}=.591, \mathrm{p}=.000$ as well as performance and emotion with $\mathrm{rs}=.578, \mathrm{p}=.000$. All other variables indicated a significant moderate association with $\mathrm{p}=.000$. The internet access was weakly correlated with all variables: skills $\mathrm{rs}=.207, \mathrm{p}=002$; emotion $\mathrm{rs}=.210, \mathrm{p}=.002$; participation $\mathrm{rs}=.199, \mathrm{p}=.003$; performance $\mathrm{rs}=.272, \mathrm{p}=.000$. (Table 2). In contrast, the highest association was shown between internet access and performance. This may indicate the internet access can account for better grades at .27 (Table 2). In sum, internet access, skills, emotions, participation or interaction, as well as performance are all correlated with statistical significance.

\section{Discussion}

The purpose of the study was to explore student engagement in online learning in a higher education institution. With this purpose, the study compared student engagement measurement with gender, a level of study, a field of study, tools to study, and internet access, and examined the relationships between variables. The research questions were if there is a difference in student engagement in online learning across gender, tools used to study, a level of study, a field they are studying, and the internet access; how students differ in engaging in online learning in terms of skills, participation or interaction, emotions and performance; and if there is an association between skills, participation or interaction, emotions, and performance with gender, tools used to study, a level of study, a field they are studying, and the internet access. 
Upon examining the variables of online student engagement, the variable of emotion indicating the feeling or affective engagement was not found to have any significant differences and associations with gender, a field of study, tools for study, internet access, and a level of study. This may indicate the lack of interpersonal interactions and the frequencies of interactions as found by Jaggars and $\mathrm{Xu}$ (2016) and less collaboration suggested by Paulsen and McCormick (2020). It also shows that online learning for the students may have been perceived to be completing tasks and assignments given by the instructor, rather than requiring devotion and being committed towards learning. Moreover, the student engagement in online learning during the pandemic period may have been extrinsically motivated as being mandatory to adapt to the pandemic situation, but not necessarily intrinsic in learning online. Thus, the items measuring emotion in student online engagement were not found to have any differences and associations.

The most significant and constant variables to measure student engagement were participation and performance. Participation indicating active connections that students are making with peers and instructors was shown to be different between male and female students. Furthermore, the association between participation and gender was also the indication of the likelihood of engagement in online learning. Connections were similarly found to be important in online learning (Dixson, 2010; Robinson \& Hulliger, 2008). Hew (2015) found the constant interaction with instructors to be the most important in student online engagement. Participation through connections and communications with other students and instructors can be varied between gender and their different approaches in online learning. Participation was also different across the fields of study the students are pursuing. Some fields may require on-site studies such as laboratory work and seminars, some may be good enough to be taught online such as lecturing.

The performance was also one of the variables that showed differences across tools, fields of study, and association with the field of study. The variable indicates the student success in the course reflecting the grades they received during the online learning. First, the tools such as if the student is using a smartphone or laptop, desktop, tablet, and if it is personally owned or borrowed from others revealed differences in the grades or the success of the course. Matias and Wolf (2013) argued that mobile technology can have some problems in online learning such as platforms, access to the wireless connection with a data plan, or Wi-fi hotspot. Performance variables may show the difference in the tools as students receive different grades with the use of different tools. Interestingly, when we look at the result of the correlation of the internet access and four student engagement variables, performance correlated the highest out of all variables with statistical significance. This may support Matias and Wolf's (2013) argument of the mediator being access to the internet. Further studies may need to examine the types of devices students use in online learning concerning student engagement as well data and wife or any other internet access.

\section{Conclusion}

The coronavirus pandemic has imposed many challenges across higher education stakeholders such as students, parents, instructors, and institutions in the country. Student online engagement illustrated that participation or interaction espoused by connectedness can be affected by gender, and performance espoused by grades they receive can be affected by the field of study. The insignificant variable, which is an emotion expressing devotion and commitment towards the study may indicate the sudden intrinsically involuntary engagement caused by the pandemic. Moreover, students may have approached their online learning as a way of task or assessment completion, but not necessarily the learning per se. Further studies should compare among countries during the lockdown.

\section{Limitation}

The data was obtained from one university which accommodates over 10.000 students from urban and countryside areas. The sample may not represent the online student engagement in other universities. Moreover, the data is more skewed towards the female participants.

\section{Acknowledgements}

I would like to extend my sincere gratitude to my colleagues Amarzaya, A., Battur, G., Davaa, J., Garmaa, D., Munkhjargal, B., Tumenjargal, D., Naranbaatar, B., and other colleagues for helping to collect the data.

\section{References}

Amemado, D. (2020). COVID-19: An unexpected and unusual driver to online education. International higher education, 102, 12-14.

Axelson, R. D., \& Flick, A. (2010). Defining student engagement. Change: The magazine of higher learning, 43(1), 38-43. https://doi.org/10.1080/00091383.2011.533096 
Bao, W. (2020). COVID-19 and online teaching in higher education: A case study of Peking University. Human Behavior and Emerging Technologies, 2(2), 113-115. https://doi.org/10.1002/hbe2.191

Chakraborty, M., \& Nafukho, F. M. (2014). Strengthening student engagement: what do students want in online courses? European Journal of Training and Development. https://doi.org/10.1108/EJTD-11-2013-0123

Colorado, J. T., \& Eberle, J. H. (2010). Web accessibility essentials for online course developers. In Web-Based Education: Concepts, Methodologies, Tools and Applications (pp. 405-417). IGI Global. https://doi:10.4018/978-1-61520-963-7.ch028

Corder, G. W., \& Foreman, D. I. (2011). Nonparametric statistics for non-statisticians. https://doi.org/10.1002/9781118165881

Dhawan, S. (2020). Online learning: A panacea in the time of COVID-19 crisis. Journal of Educational Technology Systems, 49(1), 5-22. https://doi.org/10.1177/0047239520934018

Dixson, M. D. (2010). Creating Effective Student Engagement in Online Courses: What Do Students Find Engaging? Journal of the Scholarship of Teaching and Learning, 10(2), 1-13.

Dixson, M. D. (2015). Measuring student engagement in the online course: The Online Student Engagement scale (OSE). Online Learning, 19(4), n4. https://doi.org/10.24059/olj.v19i4.561

Ellis, R. A., \& Bliuc, A. M. (2019). Exploring new elements of the student approaches to learning framework: The role of online learning technologies in student learning. Active Learning in Higher Education, 20(1), 11-24. https://doi.org/10.1177/1469787417721384

Erkhembayar, R., Dickinson, E., Badarch, D., Narula, I., Thomas, G. N., Ochir, C., \& Manaseki-Holland, S. (2020). Early policy actions and emergency response to the COVID-19 pandemic in Mongolia: experiences and challenges. The Lancet Global Health. https://doi.org/10.1016/S2214-109X(20)30295-3

Field, A. (2013). Discovering statistics using IBM SPSS statistics. Sage.

Fredricks, J. A., Blumenfeld, P. C., \& Paris, A. H. (2004). School engagement: Potential of the concept, state of the evidence. Review of educational research, 74(1), 59-109. https://doi.org/10.3102/00346543074001059

Handelsman, M. M., Briggs, W. L., Sullivan, N., \& Towler, A. (2005). A measure of college student course engagement. The Journal of Educational Research, 98(3), 184-192. https://doi.org/10.3200/JOER.98.3.184-192

Henrie, C. R., Halverson, L. R., \& Graham, C. R. (2015). Measuring student engagement in technology-mediated learning: A review. Computers \& Education, 90, 36-53. https://doi.org/10.1016/j.compedu.2015.09.005

Hew, K. F. (2015). Towards a model of engaging online students: lessons from MOOCs and four policy documents. International Journal of Information and Education Technology, 5(6), 425. https://doi.org/10.7763/IJIET.2015.V5.543

Hu, M., \& Li, H. (2017, June). Student engagement in online learning: A review. In 2017 International Symposium on Educational Technology (ISET) (pp. 39-43). IEEE. https://doi.org/10.1109/ISET.2017.17

Jacobs, Pearl. (2013)."The Challenges of Online Courses For The Instructor." Research in Higher Education Journal, 2l(2013), 1-18.

Jaggars, S. S., \& Xu, D. (2016). How do online course design features influence student performance? Computers \& Education, 95, 270-284. https://doi.org/10.1016/j.compedu.2016.01.014

Johnson, N., Veletsianos, G., \& Seaman, J. (2020). US Faculty and Administrators' Experiences and Approaches in the Early Weeks of the COVID-19 Pandemic. Online Learning, 24(2), 6-21. https://doi.org/10.24059/olj.v24i2.2285

Kahn, P., Everington, L., Kelm, K., Reid, I., \& Watkins, F. (2017). Understanding student engagement in online learning environments: The role of reflexivity. Educational Technology Research and Development, 65(1), 203-218. https://doi.org/10.1007/s11423-016-9484-z

Kahu, E. R. (2013). Framing student engagement in higher education. Studies in higher education, 38(5), 758-773. https://doi.org/10.1080/03075079.2011.598505

Keengwe, J., \& Kidd, T. T. (2010). Towards best practices in online learning and teaching in higher education. MERLOT Journal of Online Learning and Teaching, 6(2), 533-541. 
Kim, K. J., \& Bonk, C. J. (2006). The future of online teaching and learning in higher education. Educause quarterly, 29(4), 22-30.

Martin, F., \& Bolliger, D. U. (2018). Engagement matters: Student perceptions on the importance of engagement strategies in the online learning environment. Online Learning, 22(1), 205-222. https://doi.org/10.24059/olj.v22i1.1092

Matias, A., \& Wolf, D. F. (2013), "Engaging Students in Online Courses Through the Use of Mobile Technology", Wankel, L. A. and Blessinger, P. (Ed.) Increasing Student Engagement and Retention Using Mobile Applications: Smartphones, Skype and Texting Technologies (Cutting-Edge Technologies in Higher Education, Vol. 6 Part D), Emerald Group Publishing Limited, Bingley, 115-142. https://doi.org/10.1108/S2044-9968(2013)000006D007

Means, B., Toyama, Y., Murphy, R., Bakia, M., \& Jones, K. (2009). Evaluation of evidence-based practices in online learning: A meta-analysis and review of online learning studies. www.ed.gov/about/offices/list/opepd/ppss/reports.html

Meyer, K. A. (Ed.). (2014). Student Engagement Online: What Works and Why: ASHE Higher Education Report, Volume 40, Number 6. John Wiley \& Sons. https://doi.org/10.1002/aehe.20018

Mongolian Statistics Office, (2020, September 2). Statistical Open Database. Retrieved November 20, 2020, from https://www.1212.mn/stat.aspx?LIST_ID=976_L20_1

Paulsen, J., \& McCormick, A. C. (2020). Reassessing disparities in online learner student engagement in higher education. Educational Researcher, 49(1), 20-29. https://doi.org/10.3102/0013189X19898690

Pilotti, M., Anderson, S., Hardy, P., Murphy, P., \& Vincent, P. (2017). Factors Related to Cognitive, Emotional, and Behavioral Engagement in the Online Asynchronous Classroom. International Journal of Teaching and Learning in Higher Education, 29(1), 145-153.

Robinson, C. C., \& Hullinger, H. (2008). New benchmarks in higher education: Student engagement in online learning. Journal of Education for Business, 84(2), 101-109. https://doi.org/10.3200/JOEB.84.2.101-109

Schroeder, C., \& Kuh, G. (2003). How are we doing at engaging students? About Campus, 8(1), 9-16. https://doi.org/10.1177/108648220300800104

Siemens (2015). Bonk, C. J., Lee, M. M., Reeves, T. C., \& Reynolds, T. H. (Eds.). (2015). MOOCs and open education around the world. Routledge.

Shapiro, S. S., \& Wilk, M. B. (1965). An analysis of variance test for normality (complete samples). Biometrika, 52(3/4), 591-611. https://doi.org/10.2307/2333709

Trowler, V. (2010). Student engagement literature review. The higher education academy, 11(1), 1-15.

Wallace, R. M. (2003). Online learning in higher education: A review of research on interactions among teachers and students. Education, Communication \& Information, 3(2), 241-280. https://doi.org/10.1080/14636310303143

World Health Organization, (2020). Covid-19 situation report for Mongolia \#28. Retrieved January 5, 2021, from https://www.who.int/mongolia/internal-publications-detail/covid-19-situation-report-for-mongolia-28-15-nove mber-2020

World Bank, (2020). The World Bank Data. Retrieved January 2, 2021, from https://data.worldbank.org/country/XN

Zoljargal, D. (2020). A Case Study of Higher Education in Mongolia: Institutional Isomorphism. International Journal of Higher Education, 9(1), 107-115. https://doi.org/10.5430/ijhe.v9n1p107

\section{Copyrights}

Copyright for this article is retained by the author(s), with first publication rights granted to the journal.

This is an open-access article distributed under the terms and conditions of the Creative Commons Attribution license (http://creativecommons.org/licenses/by/4.0/). 